\title{
Impact of Packaging Materials on Quality of Fresh Cut Pineapple Using Biopreservative to Ensure Safety
}

\author{
G. Sindumathi*, S. Amutha and V. Kavitha \\ Department of Food Science and Nutrition, Home Science College and Research Institute, Tamil \\ Nadu Agricultural University, Madurai-625 104, Tamil Nadu, India \\ *Corresponding author
}

\author{
A B S T R A C T
}

Packaging of a food product is an operation, which aims at the prevention of all kinds of degradation that renders it unsuitable for consumption or of a lower sensorial value. Fresh

\section{Keywords}

Fresh-cut pineapple, Nisin, Packaging materials,

Temperature, Storage.

Article Info

Accepted:

07 October 2017

Available Online:

10 December 2017 cut products are experiencing an increasing popularity mainly due to their convenience, freshness and associated health benefits. Pineapple is appreciated for its taste, flavour. Juiciness and has many medicinal properties of bromelin which is found in pineapple regulates and cures many diseases. Pineapple were minimally processed in the form of slices and treated with $0.04 \mathrm{mg}$ of nisin packed in thermocol, arecanut sheath, aluminium foil and polypropylene stored at room and refrigeration temperatures. Changes in physiological loss of weight, firmness, TSS, pH, ascorbic acid, $\beta$-carotene, total antioxidant activity, sensory quality and microbial growth were evaluated over a time. For all the packaging materials polypropylene allowed conservation of fresh cut pineapples treated with nisin without undesirable changes up to 3 days in room temperature and 12 days in refrigerated temperature in all parameters. Packaging materials used in this study are beneficial to food industry and consumers since they can extend the lag-period and reduce the growth rate of microorganism to prolong shelf life of fresh cut pineapple to maintain food safety.

\section{Introduction}

Pineapple (Ananas comosus) is the world's most popular non-citrus tropical and subtropical fruit. It has cylindrical shape, square shoulders, an intense orange-yellow shell colour and a medium to large size (1.3 to $2.5 \mathrm{~g}$ ), and stands out for its excellent quality and sensory characteristics. The flesh is clear yellow, very sweet, compact and fibrous and has a high ascorbic acid content but low total acidity. Bromelain is a complex mixture of substances that can be extracted from the stem and core fruit of the pineapple and has serious impact on health and medicinal benefits.
It contains high amounts of vitamin $\mathrm{C}$ and manganese thiamine, $\mathrm{B}$ vitamin, dietary fibre which is important for antioxidant defense and involved in energy production (Anonymous, 2017).

Fresh cut fruits and vegetables with the advantage of health, convenience, high nutrition and flavour while still maintaining freshness, have gained great popularity among customers worldwide. This has led to a global trend of increased consumption and research investment of fresh cut fruits and 
vegetables in recent years (Oliveira et al., 2015, Siddiq Sogi and Dolan, 2013).

Fresh pineapple possesses a thick inedible peel and a large crown which takes up storage space and results in higher transportation cost (James and Ngarmsak, 2010). Value addition by processing into a ready-to-eat product is an attractive alternative since consumers will spend less time on food preparation (Rocculi et al., 2009). However, fruit peeling and cutting increase metabolic activities such as respiration rate and delocalisation of enzymes and substrates leading to quality deterioration such as browning, softening, off-flavour and microbial growth, resulting in a short shelf life (Montero-Calderon et al., 2008).

In general, traditional preservation methods of fresh cut fruits and vegetables could be broadly classified into three categories namely physical based preservation, chemical based preservation and biopreservation technology (Krasaekoopt and Bhandari, 2010). Cold storage is one of the most commonly used physical based methods to improve shelf life of fresh cut fruits and vegetables. In terms of chemical based preservation technology, a number of natural or synthetic preservatives have been used to prolong the shelf life of fresh cut fruits and vegetable in the past decades (Meireles et al., 2016). However consumers have also become more critical of the use of synthetic additives as their awareness of health and food safety has increased. This has called for the synthetic additive free or natural additive based preservation techniques in recent years.

As for traditional biopreservation with a long history of safe use it refers to the rational utilization of the antimicrobial potential of natural microorganisms and their antibacterial products to extend the shelf life and enhance the safety foods (Stiles, 1996). With the rapid development of biotechnology in the fast few decades, particular attention has been paid to novel biopreservation techniques, including the uses of bacteriophages, bacteriocins and bioprotective microorganisms.

Nisin is good example of commercial success and a good perspective is open to continue the study and development of new bacteriocins and their biotechnological applications (Parada et al., 2007). Nisin possesses a broader antimicrobial spectrum than most other bacteriocins, has been shown to be of no or low toxicity, has proven success as a food preservative, and is produced commercially in the form of so-called "nisin concentrate".

The inhibitory effect of nisin is broader than most bacteriocins and extends to a wide variety of gram positive bacteria including spore formers (Abee and Broughton, 2003

Packaging of a food product is an operation, which aims at the prevention of all kinds of degradation that renders it unsuitable for consumption or of a lower sensorial value. Fresh cut products are experiencing an increasing popularity mainly due to their convenience, freshness and associated health benefits. Thus the objective of this study was to evaluate the effects of packaging materials on the physico chemical properties, microbiological and sensory quality of fresh cut pineapple using different concentrations of nisin during refrigeration and room temperature.

\section{Materials and Methods}

\section{Materials}

Local varieties of pineapples (Ananas comosus) were purchased from the market at Madurai city. Pineapple fruit of regular shape and uniform size without any defect were selected. Fruit at maturity stage 5 (about 50\% of eyes were orange yellow, half ripe fruit) 
were used. The stage of maturity was determined based on the Malaysian standard by Federal Agricultural Marketing Authority (FAMA) (Shamsudin et al., 2009.).

Food grade quality of nisin was used in powder form was used as preservative. Packaging materials such as aluminium foil, arecanut sheath, polypropylene, thermocol container were purchased from local market. The containers were of $200 \mathrm{~g}$ capacity each made up of different kind of material. Cling wrap was used for covering the fresh cut pineapple packed in different containers.

\section{Preparation of fresh cut pineapple sample}

Working area, cutting boards, knives, containers and other utensils and surfaces in contact with fruit during processing were washed and sanitized with $200 \mu \mathrm{LL}^{-1}$ sodium hypochlorite solutions at $\mathrm{pH}$ to have a maximum sanitizing effect prior to processing. The selected fruits were peeled and cut superficially in order to remove the eyes, washed in running tap water followed by washing in chlorine solution (200ppm) for 2 minutes to keep surface $\mathrm{pH}$ low enough to reduce microbial growth and to improve tissue firmness ; excess water was drained for 2 minutes. Then pineapples were cut with a sharp knife into cubes of $2 \mathrm{~cm}$ (Fig. 1).

\section{Application of Nisin}

Nisin dissolves well in low $\mathrm{pH}(3-4)$ condition. Nisin solution ( $\mathrm{pH} 3-4)$ was prepared by dissolving citric acid solution in different concentrations of $0.04,0.05$ and $0.06 \mathrm{mg}$. The fresh cut pineapples were pretreated by soaking them in the above solutions for 5 to 10 minutes. Then it was surface dried for one hour and packed in thermocol container and the samples were stored at room and refrigeration temperatures for its storage stability.

\section{Determination of antimicrobial activity of nisin}

Isolates of nisin were very separately grown in test tubes without agitation in $10 \mathrm{ml}$ Man Rogosa Sharpe (MRS) broth. The broth culture was incubated at $35^{\circ} \mathrm{C}$, for $42 \mathrm{~h}$. After incubation the culture was centrifuged (10,000 rpm for 10 minutes) to obtain the culture supernatant.

The $\mathrm{pH}$ of the culture supernatant was adjusted to $\mathrm{pH} 7$ with $1 \mathrm{~N} \mathrm{NaOH}$ and again filtered using membrane filter. Sterile filter paper disc were dipped into the above sterile culture filtrate of LAB and placed on nutrient agar seeded with test microorganisms. The plates are kept at $4^{\circ} \mathrm{C}$ for 3 to $4 \mathrm{~h}$ to permit diffusion the assay material and then incubated at $37^{\circ} \mathrm{C}$ for 24 hours. The disc dipped in uninoculated MRS broth served as control.

\section{Standardization of level of concentrations of nisin}

The colour, appearance, firmness, flavour, taste and general acceptance of fresh cut pineapple using different concentrations of nisin was determined by the method described by Alegria et al., (2009). It was evaluated by panel of trained judges using 1-5 scale by using thermocol as storage container.

\section{Standardization of packaging material}

Fresh cut pineapple treated with nisin was packed in thermocol container as a common packaging material. For each preservative the best concentration level of $0.04 \mathrm{mg}$ of nisin was selected for further studies using the different packaging material such as arecanut sheath, aluminium foil and polypropylene with covering of cling wrap and stored in room and refrigeration temperatures. The untreated pineapple served as control. 


\section{Methods}

\section{Storage studies}

Chemical and physical analyses were done periodically once in a day for fresh cut fruits and vegetables stored at room temperature and on alterative days for the samples stored under refrigeration as per the procedures given below.

\section{Determination of physical characteristics}

Weight loss of the fresh cut pineapple sample was determined by comparing the weights of samples during the end of the storage with initial weights by using a digital balance (Electronic balance shimadzu, B.L-120-H) and expressing the results as a percentage (Chien et al., 2007). Firmness of the treated fresh cut pineapple was evaluated during the storage period with a texture analyser (Texture analyzer stable micro system, model: Texture Export Version 1.22) Treated Fresh cut pineapple were placed on the platform horizontally and cut with the speed of 1.0 $\mathrm{mm} / \mathrm{s}$ and the distance of cut was $10 \mathrm{~mm}$. The firmness of the treated fruits and vegetables was tested during the storage period and reported as peak force of cutting and expressed in Newtons (N) (Rocculi et al., 2009).

\section{Determination of chemical constituents}

The $\mathrm{pH}$ of the samples was estimated by the method described by Hurt and Fischer (1971). Five grams of the sample was mixed well using a glass rod in $50 \mathrm{ml}$ of distilled water and the $\mathrm{pH}$ of the suspension was determined using $\mathrm{pH}$ meter. Total soluble solids were measured by using hand refractrometer and expressed as degree Brix (Ranganna, 1995). Ascorbic acid was estimated following the procedure of Mahadevan and Sridhar (1986).The amount of ascorbic acid present in the sample was calculated and expressed as mg per $100 \mathrm{~g}$.

The $\beta$ carotene of the sample was estimated colorimetrically as described by Raghuramulu et al., (1983) expressed as microgram per $100 \mathrm{~g}$ of the sample. Antioxidant assay was measured using UV-Scan spectrophotometer at $593 \mathrm{~nm}$ spectrophotometrically (Benzie and Strain, 1996).

\section{Microbiological examination}

The microbial load (bacteria, fungi and yeast) of the stored sample were enumerated at regular intervals by the method described by Istavankiss (1984). All microbiological analysis was carried out in triplicate and the results were expressed as $\log _{10}$ colony forming units per grams $\left(\log _{10} \mathrm{CFU} / \mathrm{g}\right)$.

\section{Organoleptic evaluation}

The fresh cut pineapples were standardized based on the method described by Alegria et al., (2009) using 1-5 scale. It was evaluated by panel of trained judges.

\section{Statistical analysis}

The data obtained were subjected to statistical analysis to find out the impact of treatments, storage period, different packaging materials, and temperatures on the quality of the products during storage. Four factorial completely randomized designs were applied for the analysis (Gomez and Gomez, 1984).

\section{Results and Discussion}

\section{Assessment of antimicrobial activity of} nisin

The antimicrobial activity of nisin was assessed by studying the area of inhibition caused by isolates on test organisms viz., 
Escherichia coli, Salmonella sp, Streptococcus sp, Enterococcus $s p$ and Bacillus sp. Inhibition growth of pathogenic bacteria by, nisin was presented in Table 1 .

Nisin showed maximum inhibition on Streptococcus sp $(14.0 \mathrm{~mm})$ followed by Escherichia coli $(13.5 \mathrm{~mm})$ Bacillus $s p$ (12.0mm), Salmonella sp (11.6mm), Enterococcus sp (11.3mm). Nisin is first bacteriocin produced by fermentation using the bacterium Lactococcus lactis. Nisin is essentially non-toxic to humans and does not lead to cross- resistance with medical antibiotics. It is commercially produced under brand name - Nisaplin. It is inhibitory to many Micrococcus, Clostridium, Bacillus and Staphylococcus etc. (Chandra et al., 2008).

\section{Standardization of level of concentrations of nisin for fresh cut pineapple}

Mean scores obtained for the fresh cut pineapple treated with different types of biopreservatives packed in thermocol container are given in the Table 2. Fresh cut pineapple treated with $0.04 \mathrm{mg}$ of nisin was highly acceptable by the judges with the score value of 1.0 for colour, appearance, firmness and flavour; 1.3 for taste and 1.2 for general acceptance. The taste and general acceptance of the fresh cut pineapple treated with $0.05 \mathrm{mg}$ and $0.06 \mathrm{mg}$ of nisin was not acceptable to the judges because it imparted slight bitter taste. The flavour was not liked by the judges. Fruit phenolics have attracted a great interest recently as potential natural antimicrobial agents that could be used to extend the shelf life of value added fruit and vegetable products. The antimicrobial activity of catechin, chlorogenic acid phloridzin 1,5, 10 and $25 \mathrm{mM}$ concentrations was assessed against three marker pathogenic bacteria, one probiotic bacterium, two yeasts and one food spoilage fungus (Muthuswamy and Rupasinghe, 2007).

\section{Physico chemical characteristics of fresh cut pineapple during storage}

\section{Physiological loss of weight (\%)}

As seen in the Figure 2 the fresh cut pineapple treated with nisin had maximum shelf life of 12 days in refrigeration temperature with the minimum loss of $0.86 \%$ in arecanut sheath container $0.80 \%$ in aluminium foil container $0.75 \%$ in polypropylene container when compared to control samples. At room temperature fresh cut pineapple had shelf life of 3 days and recorded weight of $1.82 \%$ in arecanut sheath, $1.70 \%$ in aluminium container and polypropylene container. The weight loss of nisin treated samples was significantly lower than untreated samples.

Rojas-Grati et al., (2007) observed that the incorporation of lemongrass into alginateapple puree edible film did not significantly affect water vapor permeability.

They noted that it could be related to the main components of this essential oil, which is not lipid and mostly contains terpene-like compounds.

\section{Firmness}

The firmness of $(\mathrm{N})$ of fresh cut pineapple treated with nisin is given in graphical representation in Figure 3. The initial firmness of fresh cut pineapple was 19.36 Newton and the final firmness values ranged from 22.28 to 25.56 Newton in control samples stored in different packaging materials. The shelf life of fresh cut pineapple stored in room temperature and refrigeration temperature was 2 days and 8 days respectively. The final firmness content nisin treated sample ranged from 22.12 to 25.30 Newton with the shelf life of 3 days at room temperature and 12 days at refrigeration temperature stored in different packaging materials. 
Table.1 Inhibition of growth of pathogenic bacteria by nisin

\begin{tabular}{|l|c|}
\hline \multirow{2}{*}{ Test organisms } & Area of Inhibition $\mathbf{( m m})$ \\
\cline { 2 - 2 } & Nisin \\
\hline Escherichia coli & 13.5 \\
\hline Salmonella $\mathrm{sp}$ & 11.6 \\
\hline Streptococcus $\mathrm{sp}$ & 14.0 \\
\hline Enterococcus $\mathrm{sp}$ & 11.3 \\
\hline Bacillus $\mathrm{sp}$ & 12.0 \\
\hline
\end{tabular}

Table.2 Mean scores obtained for standardization level of concentration of nisin

\begin{tabular}{|l|c|c|c|c|c|c|}
\hline \multirow{2}{*}{$\begin{array}{c}\text { Concentration level } \\
\text { of nisin }\end{array}$} & \multicolumn{6}{|c|}{ Mean scores obtained for the various sensory parameters (1-5 scale) } \\
\cline { 2 - 7 } & Color & Appearance & Firmness & Flavor & Taste & General acceptance \\
\hline $\mathbf{0 . 0 4} \mathrm{mg}$ & $\mathbf{1 . 0}$ & $\mathbf{1 . 0}$ & $\mathbf{1 . 0}$ & $\mathbf{1 . 0}$ & $\mathbf{1 . 3}$ & $\mathbf{1 . 2}$ \\
\hline $0.05 \mathrm{mg}$ & 1.0 & 1.0 & 1.0 & 1.5 & 2.2 & 2.5 \\
\hline $0.06 \mathrm{mg}$ & 1.0 & 1.0 & 1.0 & 1.8 & 2.5 & 2.8 \\
\hline
\end{tabular}

\begin{tabular}{|l|l|l|l|l|l|}
\hline \multicolumn{1}{|c|}{ Color } & $\begin{array}{l}\text { 1-Very dark } \\
\text { yellow }\end{array}$ & 2- Dark yellow & 3-Yellow & 4-Light yellow & $\begin{array}{l}\text { 5-Very light } \\
\text { yellow }\end{array}$ \\
\hline Appearance & 1-Excellent & 2-Very good & 3-Good & 4-Fair & 5-Poor \\
\hline Firmness & 1-very firm & 2-Firm & 3-Moderate & 4-soft & 5-Very soft \\
\hline Flavour & 1-Very intense & 2-Intense & 3-Moderate & 4-Low & 5-Absent \\
\hline Taste & 1-Excellent & 2-Very good & 3-Good & 4-Fair & 5-Poor \\
\hline $\begin{array}{l}\text { General } \\
\text { acceptance }\end{array}$ & $\begin{array}{l}\text { 1-Excellent } \\
\text { freshly cut }\end{array}$ & 2-Good & $\begin{array}{l}\text { 3-Limit of } \\
\text { marketability }\end{array}$ & $\begin{array}{l}\text { 4-fair limit of } \\
\text { usability }\end{array}$ & $\begin{array}{l}\text { 5-Poor } \\
\text { usable }\end{array}$ \\
\hline
\end{tabular}

Table.3 Nutrient content of fresh cut pineapple treated with nisin during storage

\begin{tabular}{|c|c|c|c|c|c|c|c|c|}
\hline \multirow{3}{*}{ Nutrients } & \multicolumn{4}{|c|}{ Control } & \multicolumn{4}{|c|}{ Nisin } \\
\hline & \multicolumn{2}{|c|}{ Room Temp. } & \multicolumn{2}{|c|}{ Refrigeration temp. } & \multicolumn{2}{|c|}{ Room Temp. } & \multicolumn{2}{|c|}{ Refrigeration temp. } \\
\hline & Initial & Final & Initial & Final & Initial & Final & Initial & Final \\
\hline \multicolumn{9}{|c|}{ ARECANUT SHEATH } \\
\hline pH & 3.95 & $4.32(2)$ & 3.95 & $4.22(8)$ & 3.95 & $4.22(3)$ & 3.95 & $4.10(2)$ \\
\hline Total soluble solids & 15.00 & $15.50(2)$ & 15.00 & $15.80(8)$ & 15.00 & $15.20(3)$ & 15.00 & $15.60(12)$ \\
\hline Ascorbic acid (mg\%) & 35.00 & $22.75(2)$ & 35.00 & $26.25(8)$ & 35.00 & $25.62(3)$ & 35.00 & $28.60(12)$ \\
\hline$\beta$-carotene $(\mu \mathrm{g} / \mathbf{1 0 0 g})$ & 15.00 & $9.50(2)$ & 15.00 & $10.75(8)$ & 15.00 & $12.42(3)$ & 15.00 & $13.65(12)$ \\
\hline $\begin{array}{l}\text { Total antioxidant activity } \\
(\mu \mathrm{g} / \mathrm{g})\end{array}$ & 19.00 & $12.00(2)$ & 19.00 & $13.00(8)$ & 19.00 & $12.30(3)$ & 19.00 & $14.10(10)$ \\
\hline \multicolumn{9}{|c|}{ ALUMINIUM FOIL } \\
\hline pH & 3.95 & $4.34(2)$ & 3.95 & $4.20(8)$ & 3.95 & $4.20(3)$ & 3.95 & $4.08(12)$ \\
\hline Total soluble solids & 15.00 & $15.50(2)$ & 15.00 & $15.80(8)$ & 15.00 & $15.20(3)$ & 15.00 & $15.60(12)$ \\
\hline Ascorbic acid (mg\%) & 35.00 & $22.84(2)$ & 35.00 & $26.54(8)$ & 35.00 & $22.95(2)$ & 35.00 & $26.67(8)$ \\
\hline$\beta$-carotene $(\mu \mathrm{g} / \mathbf{1 0 0 g})$ & 15.00 & $9.56(2)$ & 15.00 & $10.86(8)$ & 15.00 & $12.60(3)$ & 15.00 & $13.70(12)$ \\
\hline $\begin{array}{l}\text { Total antioxidant activity } \\
(\mu \mathrm{g} / \mathrm{g})\end{array}$ & 19.00 & $12.10(2)$ & 19.00 & $13.50(8)$ & 19.00 & $12.35(3)$ & 19.00 & $15.50(12)$ \\
\hline \multicolumn{9}{|c|}{ POLYPROPYLENE CONTAINER } \\
\hline pH & 3.95 & $4.36(2)$ & 3.95 & $4.20(8)$ & 3.95 & $4.18(3)$ & 3.95 & $4.06(12)$ \\
\hline Total soluble solids & 15.00 & $15.50(2)$ & 15.00 & $15.80(8)$ & 15.00 & $15.20(3)$ & 15.00 & $15.60(12)$ \\
\hline Ascorbic acid (mg\%) & 35.00 & $22.95(2)$ & 35.00 & 26.67 & 35.00 & $25.82(3)$ & 35.00 & $28.90(12)$ \\
\hline$\beta$-carotene $(\mu \mathrm{g} / \mathbf{1 0 0 g})$ & 15.00 & $9.67(2)$ & 15.00 & $10.90(8)$ & 15.00 & $12.69(3)$ & 15.00 & $13.78(8)$ \\
\hline $\begin{array}{l}\text { Total antioxidant activity } \\
(\mu \mathrm{g} / \mathrm{g})\end{array}$ & 19.00 & $12.15(2)$ & 19.00 & $13.60(8)$ & 19.00 & $12.46(3)$ & 19.00 & $16.00(12)$ \\
\hline
\end{tabular}

(Figures in parenthesis indicate the storage days) 
Table.4 Microbial analysis of fresh cut pineapple treated with nisin during storage

\begin{tabular}{|c|c|c|c|c|c|c|c|c|}
\hline \multirow{3}{*}{ Nutrients } & \multicolumn{4}{|c|}{ Control } & \multicolumn{4}{|c|}{ Nisin } \\
\hline & \multicolumn{2}{|c|}{ Room Temp. } & \multicolumn{2}{|c|}{$\begin{array}{l}\text { Refrigeration } \\
\text { temp. }\end{array}$} & \multicolumn{2}{|c|}{ Room Temp. } & \multicolumn{2}{|c|}{ Refrigeration temp. } \\
\hline & Initial & Final & Initial & Final & Initial & Final & Initial & Final \\
\hline \multicolumn{9}{|c|}{ ARECANUT SHEATH } \\
\hline Bacteria $\left(10^{6} \mathrm{cfu} / \mathrm{g}\right)$ & 4.00 & $14.00(2)$ & 4.00 & $8.50(8)$ & 3.00 & $12.16(3)$ & 3.00 & $7.25(12)$ \\
\hline Fungi (x 10³ cfu/g) & 4.00 & $8.50(2)$ & 4.00 & $9.30(8)$ & 2.00 & $5.20(3)$ & 2.00 & $6.40(12)$ \\
\hline \multicolumn{9}{|c|}{ ALUMINIUM FOIL } \\
\hline Bacteria $10^{6} \mathrm{CFU} / \mathrm{g}$ & 4.00 & $14.00(2)$ & 4.00 & $8.35(8)$ & 3.00 & $12.00(3)$ & 3.00 & $7.20(12)$ \\
\hline Fungi (x 10³ cfu/g) & 4.00 & $8.20(2)$ & 4.00 & $9.00(8)$ & 2.00 & $5.00(3)$ & 2.00 & $6.20(12)$ \\
\hline \multicolumn{9}{|c|}{ POLYPROPYLENE CONTAINER } \\
\hline Bacteria $10^{6} \mathrm{CFU} / \mathrm{g}$ & 4.00 & $14.00(2)$ & 4.00 & $8.35(8)$ & 3.00 & $12.00(3)$ & 3.00 & $7.00(12)$ \\
\hline Fungi (x $\left.10^{3} \mathrm{cfu} / \mathrm{g}\right)$ & 4.00 & $8.00(2)$ & 4.00 & $9.00(8)$ & 2.00 & $5.00(3)$ & 2.00 & $6.00(12)$ \\
\hline
\end{tabular}

(Figures in parenthesis indicate the storage days)

Fig.1 Experimental process followed to obtain fresh cut pineapple

Selection of pineapple

Л

Peeling

ת

Removal of eyes

Washing with chlorine solution (200 ppm)

\]

Draining for $2 \mathrm{~min}$.

Л

Cutting into Slices $2 \times 2 \mathrm{~cm}$

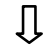

Weighing (200g)

ป

Soaking

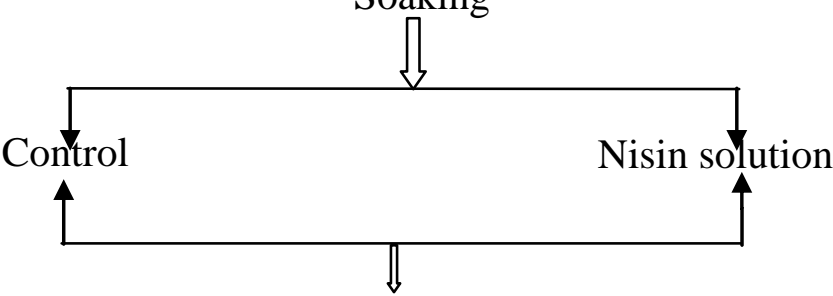

Draining

$\sqrt{ }$

Packaging

,

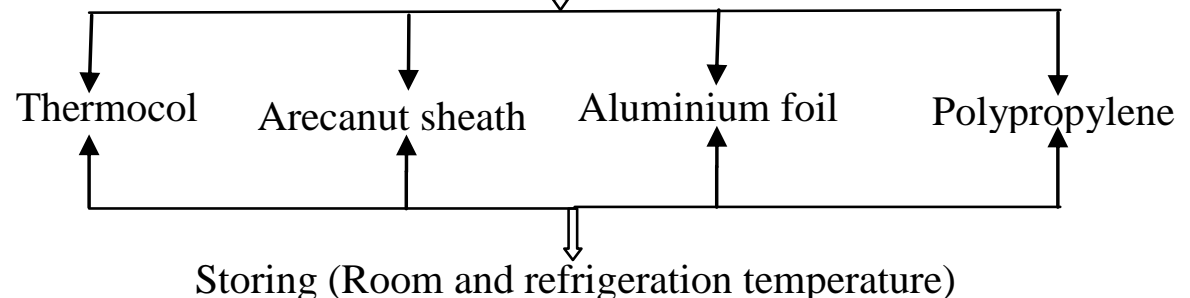

Storing (Room and refrigeration temperature) 
Fig.2 Physiological loss of weight of treated fresh cut pineapple during storage

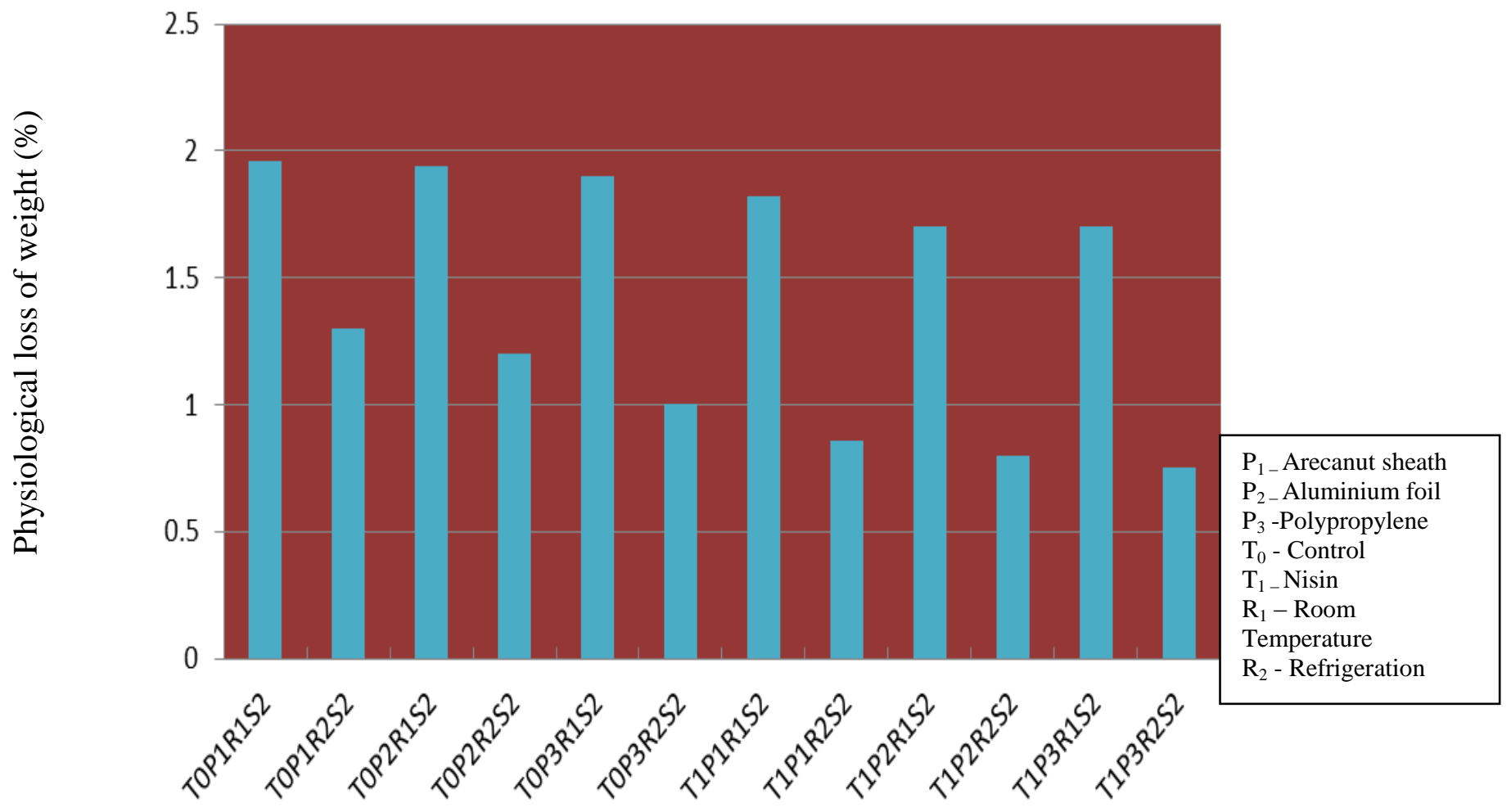

Fig.3 Firmness of fresh cut pineapple treated with nisin during storage (Newton)

\section{Firmness of fresh cut pineapple treated with nisin during storage (Newton)}

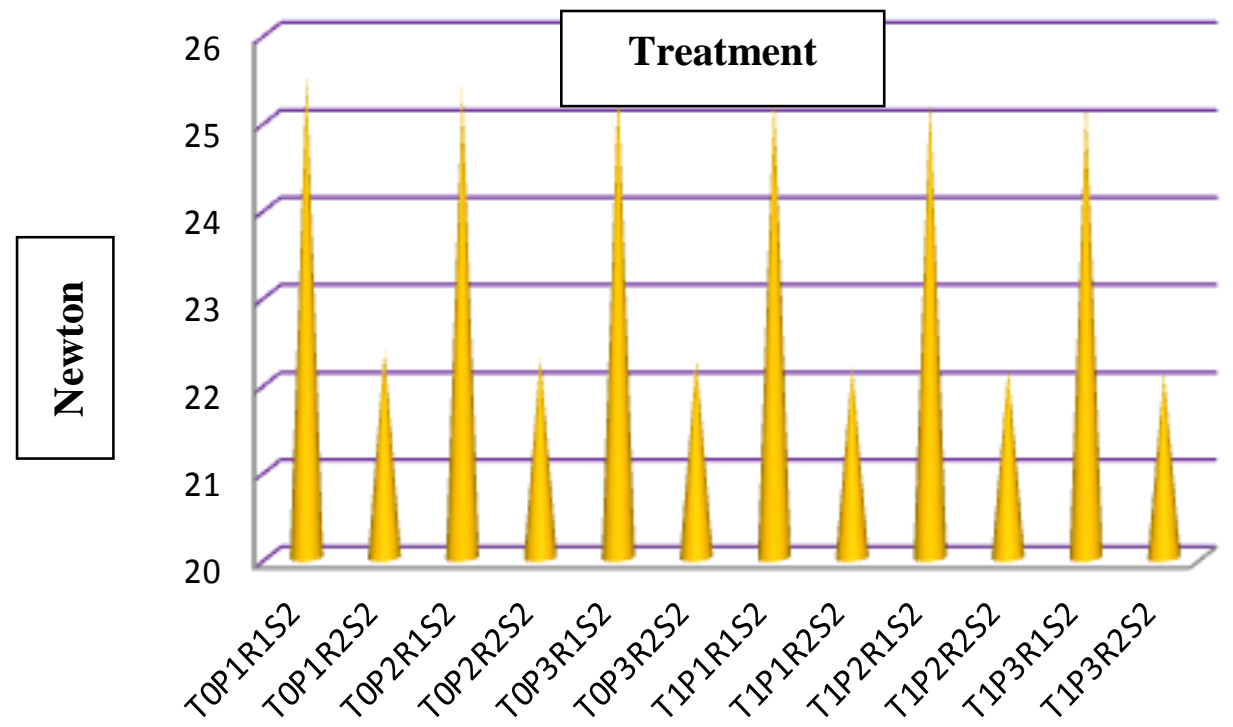

Series1

$\mathrm{P}_{1-}$ Arecanut sheath $\mathrm{P}_{2-}$ Aluminium foil

$\mathrm{P}_{3}$-Polypropylene

$\mathrm{T}_{0}$ - Control

$\mathrm{T}_{1-}$ Nisin

$\mathrm{R}_{1}-$ Room

Temperature

$R_{2}$ - Refrigeration 
Results obtained in this study showed that the nisin treated samples could significantly maintain the firmness to untreated samples during 12 days of storage. Similar results were observed by Ferrer and Harper, (2005). They confirmed that the firmness in control group of fresh cut pineapple at 6 and 12 days was significantly different from methyl jasmonate treatments. In both methyl jasmonate treatments, the fruits maintained a better fresh like texture. After 12 days, the control fruits last $66 \%$ of their initial firmness, while methyl jasmonate fruits had only an $11 \%$ and $16 \%$ loss in firmness for vapor and dipping treatments respectively.

\section{Nutrient content of fresh cut pineapple treated with nisin during storage}

The nutrient content of fresh cut pineapple treated with nisin during storage is given in Table 3. The initial $\mathrm{pH}$ of control samples was 3.95 and the final $\mathrm{pH}$ values ranged from 4.20 to 4.36 for control samples stored in different packaging materials. A minimum reduction of $\mathrm{pH}$ was observed in nisin treated fresh cut pineapple during storage period. King and Bolin (1989) observed a reduction of $\mathrm{pH}$ in case of fruits having a $\mathrm{pH}$ of 4.5 and above also functioned as an effective hurdle in improving the shelf stability of minimally processed products.

Initially the TSS content of control samples and treated fresh cut pineapple was $15.00^{\circ}$ Brix in room and refrigeration temperature in all the packaging material. Fresh cut pineapple treated with nisin had the TSS content of $15.20^{\circ}$ Brix after 3 days storage in room temperature which was packed in all the packaging material. Similarly in refrigerated temperature there was minimum decrease in the nisin treated fresh cut pineapple with value of $15.60^{\circ}$ Brix in all the packaging material after 12 days of storage respectively. Generally, the sugar content increases after harvesting but it decreases with increase of the storage period due to its utilization during respiration as an energy source. Similar trend was observed in this study.

Vitamin $\mathrm{C}$ is nutritionally an important nutrient and highly susceptible to decompose during storage. It was reported that temperature, oxygen, concentration of secondary metabolites, presence of metals (iron, copper) influence the vitamin content of final product. According to Nunes et al., (1998), the increase of ascorbic acid concentration on a fresh weight basis at higher temperature may be due to water loss during storage rather than to actual increase in ascorbic acid content. Similar changing trends of ascorbic acid in fresh cut pineapple treated with nisin packed in polypropylene was 25.82 mg per cent at room temperature with a shelf life of 3 days. $28.90 \mathrm{mg}$ per cent in refrigeration temperature with the shelf life of 12 days.

The initial $\beta$-carotene content of fresh cut pineapple in all the treatment was 15.00 $\mu \mathrm{g} / 100$ grams. The retention of $\beta$-carotene in fresh cut pineapple at refrigeration temperature was higher when compared to the fresh cut pineapple stored at room temperature. The fresh cut pineapple treated with nisin packed in polypropylene container had a longer shelf life at room and refrigeration temperature. The total carotenoids content of pineapple cubes was decrease during storage at $5^{\circ} \mathrm{C}$ after 3 days of storage. In total carotenoids of fresh cut pineapples resulting in a $25 \%$ a reduction relative to the whole fruit (Gil et al., 2006).

The initial total antioxidant activity was $19.00 \mu \mathrm{g} / \mathrm{g}$ in control and all the treatments. In the case of fresh cut pineapple treated nisin the total antioxidant activity ranged from 12.30 to $16.00 \mu \mathrm{g} / \mathrm{g}$ stored in differed packaging material of at room and 
refrigerated temperature after 3 days and 12 days of storage respectively. Lopes et al., (2017) confirmed that pulse light could substantially impact quality criteria of fresh cut mangoes. They indicated that 4 pulses of $0.7 \mathrm{~J} \mathrm{~cm}^{-2}$ were the most effective for increasing the antioxidant activity after 7 days of storage at $6^{\circ} \mathrm{C}$. Beirne and Kenny, (2009) have been expressed about possible losses of antioxidants in fresh-cut produce as a result of processing and storage.

Microbial characteristics of fresh cut pineapple treated with nisin during storage

The number of colony forming units (cfu) of bacteria observed for fresh cut pineapple treated with biopreservatives and chemical preservatives stored under room and refrigerated conditions in different packaging materials with reference to storage periods given in Table 4

The bacterial population was decreased during the storage period for samples treated with biopreservatives compared to control samples. The bacterial count was increased and the values were $7.00 \times 10^{-6}$ in nisin treated after 12 days of refrigerated temperature packed in polypropylene. Sharma and Gautam (2007) investigated that the potent bacteriocins of Lactobacillus brevis and Bacillus mycoides were evaluated to control pathogens/spoilage causing bacteria in different food samples viz. apple juice, cheese and milk. The application of bacteriocin as food preservative has shown very encouraging results.

\section{Microbial load- Fungi $\times 10^{-3} \mathrm{cfu} / \mathrm{g}$}

The fungal population was least in fresh cut pineapple treated with nisin than control sample, at room and refrigeration temperature. Comparing the effect of packaging material polypropylene was found to be better than arecanut sheath and aluminium foil container. The final fungal population in fresh cut pineapple treated stored at refrigeration temperature was $6.00 \times 10^{-3}$ packed in polypropylene container after 12 days of storage. According to the institute of Food Science and Technology (IFST) $10^{6} \mathrm{CFU} / \mathrm{g}$ is considered the limit of acceptance of fruit based products during the study of shelf life (Bierhals, 2011). Fresh cut fruit have a large area of cut surface with high moisture conditions and a rich source of nutrients, which provides a good environment for growth of microorganisms (Oms- Oliu et al., 2010). Results obtained in this study showed the total plate count of bacterial and fungi increased during storage.

\section{Sensory analysis}

The quality attributes like appearance, flavour, taste and over all acceptability values exhibited maximum score for fresh cut pineapple treated nisin whereas decreasing trend was observed in control samples at the end of storage. The effects of packaging material slightly affect the organoleptic characteristics of fresh cut pineapple.

In conclusion, nisin may provide a novel, safe alternative end effective hurdle which combined with control samples such as $\mathrm{pH}$ and temperature, can maximize protection from food borne pathogens on fresh cut products.

Nisin treated fresh cut pineapple reduced weight loss, nutrient loss, bacterial and fungal while maintained the firmness, sensory characteristics of fresh cut pineapple during low temperature storage. Packaging materials used in this study are beneficial to food industry and consumers since they can extend the lag-period and reduce the growth rate of microorganism to prolong shelf life of fresh cut pineapple to maintain food safety. 


\section{References}

Abee, T. and Broughton, J.D. 2003. Bacteriocins-Nisin. Food preservative. Springer International Edition, Kluwer Academic / Plenum Publishers, New York, 146-147.

Alegria, C., Pinheiro, J., Goncalves, E. M., Fernades, I., Moldao, M. and Abreu, M. 2009. Quality attributes of shredded carrot (Daucus carota L. cv. Nantes) as affected by alternative decontamination processes to chlorine. Innovative Food Science and Emerging Technologies. 10:1061-69.

Anonymous, 2017 www.whfoods.com

Beirne, D and Kenny, O. 2009. http://www.actahort.org/

Benzie, I.F.F. and Strain, J. J. 1996. The ferric reducing ability of plasma (FRAP) as a measure of antioxidant power. The FRAP assay. Analytical Biochemistry 70(6): 239.

Biehals, V.S., Chiumarelli, M., Hubinger, M.D., 2011. Effect of cassava starch coating on quality and shelf life of fresh-cut pineapple. Food Science 76.62-72.

Chandra, S., Durveshkumari, S. K., Goyal. and Samsher. 2008. Antifungal food additives: Can it preserve foods. Beverage and Food World. 34(2): 3640.

Chien, P.J., Sheu, F., Yang, F.H., 2007. Effects of edible chitosan coating on quality and shelf life of sliced mango fruit. Journal of Food Engineerin. 78225-229.

Ferrer, M. M. and Harper C. 2005. Reduction in microbial growth and improvement of storage quality in fresh cut pineapple after methyl jasmonate treatment. Journal of Food Quality. 28:3-12.

Gil, M.I., Aguayo, E. and Kader, A.A. 2006. Quality changes and nutrient retention in fresh cut versus whole fruits during storage. Journal of Agricultural and Food Chemistry. (12): 4284-4296.

Gomez, K. H. and Gomez, A. A. 1984. Statistical procedures for Agricultural Research. John Wiley and Sons. New York. 381.

Hurt, A. M. and Fischer, H. J. 1971. Modern Food Analysis Springer Veslag. Berlin. 64-66.

Istavankiss, S. S. 1984. Testing methods in food microbiology. Elsevier Publication Limited, 95-397.

James, J.B., Ngarmsak, T. 2011. Processing of fresh cut tropical fruits and vegetables: Atechnical guide. In. R.S, Rolle (Ed.), (pp.83). Bangkok: FAO Regional office for Asia and the pacific.

King, A.D. and Bolin, H.R. 1989. Physiological and microbiological storage stability of minimally processed fruits and vegetables. Food Technology. 43(2): 132-135.

Krasaekoopt, Wand Bhandari, B 2010. Freshcut vegetables. Hand book of vegetables and vegetable processing. Wiley-Black well. p.219-242.

Lopes, MMA., Silva E.O., Laurent.S., Charles, F., Urban L., Miranda, M.R.A., 2017. The influence of pulsed light exposure mode on quality and bioactive compounds of fresh-cut mangoes. Journal of Food Science and Technology. 17 35-39.

Mahadevan. and Sridhar. 1986. Methods in physiological plant pathology. Sivakami publication. $3^{\text {rd }}$ edition. Madras. 146147.

Meireles, A Giaouris, E and Simoes, M 2016. Alternative disinfection methods to chlorine for use in the fresh cut industry. Food Research International 82. 71-85.

Montero-Calderon, M., Rojas-Grau, M.A., Martin-Belloso, O., 2008. Effect of packaging conditions on quality and shelf life of fresh -cut pineapple 
(Ananas comosus). Post Harvest Biological Technology. 50, 182-189.

Muthuswamy, S. and Rupasinghe, H.P.V. 2007. Fruit phenolics as natural antimicrobial agents: selective antimicrobial activity of catechin, chlorogenic acid and phloridzin. Journal of Food Agricultural and Environment. 5(3\&4):81-85.

Nunes MCN, Brecht J.K., Morais AMMB, Sargent SA. 1998. Controlling temperature and water loss to maintain ascorbic acid levels in strawberries during post harvest handling. Journal of Food Science 63:1033-1036.

Oliveira, Mabadias, M., Colas-Meda, P., Usall, J and Vina, I. 2015. Application of modified atmosphere packaging as a safety approach to fresh cut fruits and vegetables- A review. Trends in Food Science and Technology 46. 13-26.

Oms-Oliu, G., Martin-Bellos, O and SolivaFortuny, R. 2010. Pulsed light treatments for food preservation. A review. Food and Bioprocess Technology. 3. 13-23.

Parada, J.L, Carolina, R. C., Adriane, B. P. and Carlos, R S. 2007. Bacteriocins from lactic acid bacteria: purification, properties and use as biopreservatives. Braziliar/Achieves of biology and Technology. 50(3): 521-542.

Raghuramulu, K.M., Nair and Sundar, S. K. 1983. A manual of laboratory techniques, National Institute of Nutrition, ICMR, Hyderabad, India. 129-130.
Ranganna, S. 1995. Hand book of analysis and quality control for fruit and vegetable products. Tata Mcgraw Hill Publishing Co., Ltd., New Delhi.

Rocculi, R., Cocci, E., Romani, S., Sacchetti, G., Dalla Rosa, M., 2009. Effect of 1MCP treatment and N2O zMAP on physiological and quality changes of fresh cut pineapple. Post Harvest Biological Technology. 51, 371-377.

Rojas-Grati, M. Araybaudi-Massilia, R.M., Soliva-Fortuny, R.C., Avena-Bustillos, R.J., McHugh, T.H., Martin-belloso, O., 2007. Apple puree-alginate edible coating as carrier of antimicrobial agents to prolong shelf life of fresh-cut apples. Post-Harvest Biological Technology. 45. 254-264.

Shamsudin, R., Daud, W.R.W., Takrif, M.S., Hassan, O., 2009. Physico-mechanical properties of the Josapine pineapple fruits. Pertanika Journal of Science and Technology. 17, 17-17-23.

Sharma, N. and Gautam, N. 2007. Use of Bacteriocin as potential biopreservatives in milk, cheese and apple juice. Beverage and Food World. 34(7): 44-47.

Siddiq, M., Sogi, D., and Dolan, K 2013 Antioxidant properties, total phenolics and quality of fresh cut 'Tommy Atkins' mangoes as affected by different pretreatment. LWT-Food Science and Technology. 53. 156-162.

Stiles, M. E. 1996. Bio preservation by lactic acid bacteria. Antonie van leeuvenboek 70: 331-345.

\section{How to cite this article:}

Sindumathi, G., S. Amutha and Kavitha, V. 2017. Impact of Packaging Materials on Quality of Fresh Cut Pineapple Using Biopreservative to Ensure Safety. Int.J.Curr.Microbiol.App.Sci. 6(12): 789-800. doi: https://doi.org/10.20546/ijcmas.2017.612.084 